\title{
Effect of Irregular Treatment on Severity of Osteoporosis in Rheumatoid Arthritis Patients
}

\author{
Saif Abdulkareem Raoof Al-Shaibani (MSc) ${ }^{1}$ \\ ${ }^{1}$ Department of Medicine, Baquba Teaching Hospital, Diyala, Iraq \\ Correspondence Address: \\ Saif Abdulkareem Raoof Al-Shaibani \\ Department of Medicine, Baquba Teaching Hospital, Diyala, Iraq \\ email: saifkareem85@gmail.com
}

Received: 21 September 2021

Accepted: 23 November 2021

Published: 25 December 2021

Diyala Journal of Medicine 2021:21(2): 83-88

\begin{abstract}
Background:Rheumatoid arthritis is a chronic systemic inflammatory disorder that is associated with progressive disability and systemic complications. One of these complications is osteoporosis. Patients with severe osteoporosis have one or more fragility fractures in addition to T-score -2.5 or lower. Osteoporosis is more prevalent in rheumatoid arthritis patients who have higher disease activity.

Objective: To show the effect of irregular treatment in patients with rheumatoid arthritis on the severity of osteoporosis.

Patients and Methods: A cross-sectional study enrolled a total of 40 female patients who had rheumatoid arthritis. The data collected from patients include disease duration, disease activity and patients' compliance to their drugs. They were sent to dual-energy $\mathrm{x}$ - ray absorptiometry scan and results were recorded.

Results: The mean age was $45.95 \pm 10.0$ years; $45 \%$ of them had rheumatoid arthritis for less than five years; $55 \%$ had a low level of disease activity; and $65 \%$ of them had received treatment irregularly. Osteoporosis was diagnosed in $60 \%$ of them and $41.7 \%$ of them had severe osteoporosis. The highest prevalence of osteoporosis among patients with rheumatoid arthritis was seen significantly among older patients, patients with longer duration of rheumatoid arthritis, those with higher activity of rheumatoid arthritis, and those with irregular treatment. More than half of those who received treatment irregularly had severe osteoporosis with a significant association between treatment regularity of rheumatoid arthritis and severity of osteoporosis.
\end{abstract}

Conclusion: Severe osteoporosis occurs in rheumatoid arthritis patients with a history of irregular treatment which occurs either due to patient incompliance or delay in diagnosis. 
Osteoporosis is more prevalent in rheumatoid arthritis patients with longer disease duration, older age, higher disease activity and those who received treatment irregularly.

Keywords: Rheumatoid arthritis, Osteoporosis, Irregular Treatment

DOI: https://doi:10.26505/DJM.21026230921, (CAuthors, 2021, College of Medicine, University of Diyala.

This is an open access article under the CC BY 4.0 license (http://creativecommons.org/licenses/by/4.0/)

\section{Introduction}

Rheumatoid arthritis (RA) is a chronic systemic inflammatory disorder that is associated with systemic complications and progressive disability [1].

These complications reflect the need for early diagnosis and starting aggressive treatment directly after diagnosis to prevent complications from the occurrence or prevent their progression if it already occurred [2]. One of these complications is osteoporosis which represents a significant cause of morbidity in patients with RA because of the increased risk of fractures in those patients [3].

Osteoporosis is characterized by decreased bone density and deterioration of bone microarchitecture which predispose patients to fragility fractures [4]. The World Health Organization (WHO) defines osteoporosis as 2.5 standard deviations of bone mineral density below that of young adults (T-score of -2.5 or lower). Patients with severe osteoporosis have one or more fragility fractures in addition to this T-score [5]. Osteoporosis is more prevalent in RA patients who have higher disease activity [6].

This means that better control of disease activity leads to a decrease the risk of occurrence of osteoporosis. This needs the patient to take RA treatment on regular regimens. Some patients do not take the treatment regularly either due to patient incompliance or due to delay in the diagnosis of disease. The aim of this study is to show the effect of irregular treatment of patients with rheumatoid arthritis on the severity of osteoporosis.

\section{Patients and Methods}

\section{Study design and population}

A cross-sectional study was done at the rheumatology department at Baqubah teaching hospital during the period from June 2020 till March 2021. A total of 40 female patients with RA were included in this study. The inclusion criteria were:

1-The patient should fulfill the 2010 American College of Rheumatology/ European League against Rheumatism classification criteria for rheumatoid arthritis [7].

2-Absence of other risk factors of osteoporosis like asthma or early menopause Prior to data collection, signed consent from each of the patients was obtained after explaining the aim of the study and ensuring the privacy of the data.

\section{Method}

The following data were collected from patients:

1- Name

2- Age

3- Disease duration from the point of symptoms occurrence 
4- Duration from starting symptoms until the diagnosis of the disease

5- Drugs used for RA and the compliance of patients to these drugs

Examination of patients was done to determine disease activity using the clinical disease activity index ( CDAI ) [8]. They were sent to dual-energy $x$-ray absorptiometry (DEXA) scan and results were recorded.

\section{Statistical analysis}

The data analysis was done using Statistical Package for Social Sciences (SPSS) version 26. The data presented as mean, standard deviation and ranges. Categorical data were presented by frequencies and percentages. Chi-square test was used to assess the association between osteoporosis and certain information, while fisher exact test was used instead when the expected frequency was less than 5. A level of $\mathrm{P}$ - value less than 0.05 was considered significant.

\section{Results}

This study included 40 female patients diagnosed with rheumatoid arthritis. The mean age was $45.95 \pm 10.0$ years; $45 \%$ of them had rheumatoid arthritis for less than five years; $55 \%$ had a low level of disease activity, and $65 \%$ of them had received treatment irregularly.

Osteoporosis was diagnosed in $60 \%$ of them and $41.7 \%$ of them had severe osteoporosis.

Table (1): Distribution of study patients by certain characteristics

\begin{tabular}{|c|c|c|}
\hline Variable & No. $(n=40)$ & Percentage $(\%)$ \\
\hline \multicolumn{3}{|l|}{ Age (Year) } \\
\hline$<40$ & 12 & 30.0 \\
\hline $40-49$ & 10 & 25.0 \\
\hline$\geq \mathbf{5 0}$ & 18 & 45.0 \\
\hline \multicolumn{3}{|c|}{ Duration of rheumatoid arthritis (Year) } \\
\hline$<5$ & 18 & 45.0 \\
\hline $5-9$ & 10 & 25.0 \\
\hline$\geq 10$ & 12 & 30.0 \\
\hline \multicolumn{3}{|c|}{ Activity of rheumatoid arthritis } \\
\hline Low & 22 & 55.0 \\
\hline Moderate & 8 & 20.0 \\
\hline High & 10 & 25.0 \\
\hline \multicolumn{3}{|c|}{ Treatment regularity of rheumatoid arthritis } \\
\hline Regular & 14 & 35.0 \\
\hline Irregular & 26 & 65.0 \\
\hline \multicolumn{3}{|l|}{ Osteoporosis } \\
\hline Yes & 24 & 60.0 \\
\hline No & 16 & 40.0 \\
\hline \multicolumn{2}{|l|}{ Severity of osteoporosis } & $\mathrm{n}=\mathbf{2 4}$ \\
\hline Severe & 10 & 41.7 \\
\hline Mild & 14 & 258.3 \\
\hline
\end{tabular}


As shown in Table (2), the highest prevalence of osteoporosis among patients with rheumatoid arthritis was seen significantly among older patients $(\mathrm{P}=$ $0.001)$, patients with a longer duration of rheumatoid arthritis $(\mathrm{P}=0.001)$, those with high activity of rheumatoid arthritis $(\mathrm{P}=$ $0.011)$, and those with irregular treatment $(\mathrm{P}=$
0.001). As shown in Table (3), all patients with rheumatoid arthritis who received treatment regularly had mild osteoporosis, while $52.6 \%$ of those who received treatment irregularly had severe osteoporosis with a significant association between treatment regularity of rheumatoid arthritis and severity of osteoporosis $\quad(\mathrm{P}=\quad 0.033)$.

Table (2): Association between osteoporosis and certain characteristics of RA patients

\begin{tabular}{|c|c|c|c|c|}
\hline \multirow[b]{2}{*}{ Variable } & \multicolumn{2}{|c|}{ Osteoporosis } & \multirow[b]{2}{*}{$\begin{array}{l}\text { Total }(\%) \\
n=40\end{array}$} & \multirow[b]{2}{*}{$P$ - value } \\
\hline & $\begin{array}{l}\text { Yes }(\%) \\
n=24\end{array}$ & $\begin{array}{l}\text { No (\%) } \\
n=16\end{array}$ & & \\
\hline \multicolumn{5}{|l|}{ Age (Year) } \\
\hline$<40$ & $2(16.7)$ & $10(83.3)$ & $12(30.0)$ & \multirow{3}{*}{0.001} \\
\hline $40-49$ & $10(100.0)$ & $0(0)$ & $10(25.0)$ & \\
\hline$\geq \mathbf{5 0}$ & $12(66.7)$ & $6(33.3)$ & $18(45.0)$ & \\
\hline \multicolumn{5}{|c|}{ Duration of rheumatoid arthritis (Year) } \\
\hline$<5$ & $4(22.2)$ & $14(77.8)$ & $18(45.0)$ & \multirow{3}{*}{0.001} \\
\hline $5-9$ & $8(80.0)$ & $2(20.0)$ & $10(25.0)$ & \\
\hline$\geq 10$ & $12(100.0)$ & $0(0)$ & $12(30.0)$ & \\
\hline \multicolumn{5}{|c|}{ Activity of rheumatoid arthritis } \\
\hline Low & $10(45.5)$ & $12(54.5)$ & $22(55.0)$ & \multirow{3}{*}{0.011} \\
\hline Moderate & $4(50.0)$ & $4(50.0)$ & $8(20.0)$ & \\
\hline High & $10(100.0)$ & $0(0)$ & $10(25.0)$ & \\
\hline \multicolumn{5}{|c|}{ Treatment regularity of rheumatoid arthritis } \\
\hline Regular & $5(35.7)$ & $9(64.3)$ & $14(35.0)$ & \multirow{2}{*}{0.001} \\
\hline Irregular & $19(73.1)$ & $7(26.9)$ & $26(65.0)$ & \\
\hline
\end{tabular}

Table (3): Association between treatment regularity of rheumatoid arthritis and severity of osteoporosis

\begin{tabular}{|c|c|c|c|c|}
\hline \multirow[b]{2}{*}{$\begin{array}{l}\text { Treatment regularity } \\
\text { of rheumatoid arthritis }\end{array}$} & \multicolumn{2}{|c|}{\begin{tabular}{|c|} 
Severity of osteoporosis \\
\end{tabular}} & \multirow[b]{2}{*}{$\begin{array}{c}\text { Total }(\%) \\
n=24\end{array}$} & \multirow[b]{2}{*}{ P - value } \\
\hline & $\begin{array}{c}\begin{array}{c}\text { Severe }(\%) \\
n=10\end{array} \\
\end{array}$ & $\begin{array}{c}\text { Mild (\%) } \\
n=14\end{array}$ & & \\
\hline Regular & $0(0)$ & $5(100.0)$ & $5(20.8)$ & \multirow{2}{*}{$\mathbf{0 . 0 3 3}$} \\
\hline Irregular & $10(52.6)$ & $9(47.4)$ & $19(79.2)$ & \\
\hline
\end{tabular}

\section{Discussion}

This study revealed that $60 \%$ of patients with rheumatoid arthritis had osteoporosis. This agrees with the results of Lee et al [9] which showed that about $50 \%$ of patients with RA in their study had osteoporosis. also agrees with the results of Hauser et al [10] which showed that up to $50 \%$ of postmenopausal females with RA had osteoporosis. The results was disagreed with the the results of Miculs et al [11] which showed that the prevalence of osteoporosis in RA patients was $10 \%$. This difference may be due to those patients included in their study was only those with disease duration less than two years which may affect the 
possibility of osteoporosis occurrence, while in our study there was no restriction regarding disease duration.

The results of this study concluded that the highest prevalence of osteoporosis was among those with older age, longer disease duration, higher disease activity, and in patients with a history of irregular usage of treatment which occur either due to patient incompliance or due to delayed diagnosis.

This agrees with the results of Van Staa et al [12] which showed that osteoporosis is more prevalent in RA patients with longstanding disease due to the effects of chronic systemic inflammation. It also agreed with the results of Lee et al [9] which mentioned that osteoporosis in RA is more prevalent among older patients due to the effect of age which is a known risk factor for osteoporosis. It also agrees with the results of Phuan-Udom et al [6] which showed that osteoporosis was more prevalent in RA patients who have higher disease activity.

During our practice, we face a number of cases that do not take effective RA treatment regularly. This occurs either due to patient incompliance or due to delay in diagnosis of the patient. This leads to less control of the systemic effect of the disease and more damage to the bone by this chronic systemic inflammation.

In this study, among those patients with osteoporosis, $41.7 \%$ were sub-grouped as having severe osteoporosis which is defined as osteoporosis plus at least one fragility fracture.As mentioned in the Table (3), $52.6 \%$ of those who received treatment irregularly had severe osteoporosis with a significant association between the treatment regularity of rheumatoid arthritis and severe osteoporosis. This indicates that the most important predictive measure for osteoporosis severity in RA patients is the regularity of treatment.

\section{Conclusions}

Severe osteoporosis occurs in RA patients with a history of irregular treatment which occurs either due to patient incompliance or delay in diagnosis. Osteoporosis is more prevalent in RA patients with longer disease duration, older age, and higher disease activity.

\section{Recommendations}

Inform patients about the importance of taking drugs on a regular basis. A study with a longer duration and the larger sample size is recommended to confirm the results of this study

Source of funding: This research was funded by ourselves and these is no other funding cover this study or manuscript preparation and publication.

Ethical clearance: This study was approved by medical ethics committee of college of medicine, university of Diyala.

\section{Conflict of interest: Nill}

\section{References}

[1]Firestein GS. Evolving concepts of rheumatoid arthritis. Nature 2003;423(6937):356-361

[2]McInnes IB, Schett G. The pathogenesis of rheumatoid arthritis. $N$ Engl $J$ Med 2011;365(23):2205-19.

[3] Xu S, Wang Y, Lu J, Xu J. Osteoprotegerin and RANKL in the pathogenesis of rheumatoid arthritis-induced osteoporosis. Rheumatol Int 2012;32(11):3397-3403. 
[4]Sözen T, Özışık L, Başaran NÇ. An overview and management of osteoporosis. Eur J Rheumatol 2017;4(1):46-56.

[5]Choi HS, Park SY, Kim YM, Kim SH, Kim KM, Chung YS. Medical treatment of severe osteoporosis including new concept of advanced severe osteoporosis. Osteoporos Sarcopenia 2016;2(1):13-19.

[6]Phuan-Udom R, Lektrakul N, Katchamart $\mathrm{W}$. The association between 10-year fracture risk by FRAX and osteoporotic fractures with disease activity in patients with rheumatoid arthritis. Clin Rheumatol 2018;37(10):26032610.

[7]Aletaha D, Neogi T, Silman AJ, Funovits J, Felson DT, Bingham CO 3rd, Birnbaum NS, Burmester GR, Bykerk VP, Cohen MD, Combe B, Costenbader KH, Dougados M, Emery P, Ferraccioli G, Hazes JM, Hobbs K, Huizinga TW, Kavanaugh A, Kay J, Kvien TK, Laing $T$, Mease $P$, Ménard HA, Moreland LW, Naden RL, Pincus T, Smolen JS, Stanislawska-Biernat E, Symmons D, Tak PP, Upchurch KS, Vencovský J, Wolfe F, Hawker G. 2010 Rheumatoid arthritis classification criteria: an American College of Rheumatology/European League Against Rheumatism collaborative initiative. Arthritis Rheum 2010;62(9):2569-2581.

[8] Aletaha D, Nell VP, Stamm T, Uffmann M, Pflugbeil S, Machold K, Smolen JS. Acute phase reactants add little to composite disease activity indices for rheumatoid arthritis: validation of a clinical activity score. Arthritis Res Ther 2005;7(4):R796806.

[9]Lee JH, Sung YK, Choi CB, Cho SK, Bang SY, Choe JY, Hong SJ, Jun JB, Kim TH, Lee J, Lee HS, Yoo DH, Yoon BY, Bae $\mathrm{SC}$. The frequency of and risk factors for osteoporosis in Korean patients with rheumatoid arthritis. BMC Musculoskelet Disord 2016;17:98.

[10]Haugeberg G, Uhlig T, Falch JA, Halse JI, Kvien TK. Bone mineral density and frequency of osteoporosis in female patients with rheumatoid arthritis: results from 394 patients in the Oslo County Rheumatoid Arthritis register. Arthritis Rheum 2000;43(3):522-530.

[11]Mikuls TR, Saag KG, Curtis J, Bridges SL Jr, Alarcon GS, Westfall AO, Lim SS, Smith EA, Jonas BL, Moreland LW; CLEAR Investigators. Prevalence of osteoporosis and osteopenia among African Americans with early rheumatoid arthritis: the impact of ethnic-specific normative data. J Natl Med Assoc 2005;97(8):1155-1160

[12]Van Staa TP, Geusens P, Bijlsma JW, Leufkens HG, Cooper C. Clinical assessment of the long-term risk of fracture in patients with rheumatoid arthritis. Arthritis Rheum 2006;54(10):3104-12. 